\title{
CLINICAL CHARACTERISTICS OF GIANT PITUITARY ADENOMAS
}

Ilovayskaya I.A., Krivosheeva Y.G., Dreval A.V., Stashuk G.A.

\section{INTRODUGTION}

Pituitary adenoma is not so rare disease as it seemed earlier. According to the most recent population based study*, giant pituitary adenomas ( $>40 \mathrm{~mm}$ ) constituted $4.8 \%$ of the whole cohort of pituitary adenomas and the SIR was $0.18 / 100,000 /$ year. Giant prolactinomas constituted $4.7 \%$ of all the prolactinomas and the SIR was $0.07 / 100,000$ /year, while giant NFA constituted $6.0 \%$ of all NFA and the SIR was $0.12 / 100,000 / y e a r$.

* [Gruppetta M., Vassallo J.//Epidemiology and Radiological Geometric Assessment of Pituitary Macroadenomas: Population Based Study/l/ Clin Endocrinol (Oxf). 2016 Mar 21].

\section{MATERIAL AND METHODS}

We analysed data of 346 patients with pituitary macroadenomas: 142 non-functional adenomas (NFA), 62 macroprolactinomas, 141 somatotropinomas from Moscow Regional Registry of pituitary macroadenomas. Pituitary tumors were considered as giant adenoma if at least one of the sizes was $>40 \mathrm{~mm}$.

MRI of the of the pituitary tumor was performed on Intera Achieva (PHILIPS company) 3.0 T with gadolinium contrast agents. We assessed the maximum linear dimension in the vertical, sagittal and frontal planes $(\mathrm{mm})$. To calculate the pituitary tumor volume following formula is used: $A B C{ }^{*} \pi{ }^{*} 4 / 3$ where $A B C$ - the size of the semi-axes (sagittal, frontal and vertical) of the tumor.

Statistical analysis of the results was carried out using the IBM statistical program SPSS Statistics 20 for Windows 7.0 with variation statistics methods for nonparametric data. The data are expressed as $\mathrm{Me}[25 \%, 75 \%]$.

Tab. 1. Patient characteristics, included in the study.

\begin{tabular}{|c|c|c|c|}
\hline $\begin{array}{c}\text { Groups } \\
\mathrm{Me}[25 ; 75]\end{array}$ & $\begin{array}{l}\text { Non-functioning } \\
\text { adenomas (NFAs) } \\
\mathrm{N}=18 \\
(0)\end{array}$ & $\begin{array}{c}\text { Prolactinomas } \\
\qquad \begin{array}{c}\mathrm{N}=6 \\
\text { (1) }\end{array}\end{array}$ & $\begin{array}{l}\text { Somatotropinomas } \\
\qquad \begin{array}{c}\mathrm{N}=6 \\
(2)\end{array}\end{array}$ \\
\hline $\begin{array}{c}\text { The age of patients } \\
\text { (years) }\end{array}$ & $\begin{array}{c}54 \\
{[38 ; 68]}\end{array}$ & $\begin{array}{c}26 \\
{[22 ; 40]}\end{array}$ & $\begin{array}{c}34 \\
{[24 ; 46]}\end{array}$ \\
\hline $\begin{array}{c}\text { Males/Females } \\
\mathrm{n} / \mathrm{n}\end{array}$ & $7 / 11$ & $3 / 3$ & $3 / 3$ \\
\hline $\begin{array}{l}\text { The vertical sizes of } \\
\text { pituitary tumor }(\mathrm{mm}) \text { : }\end{array}$ & $\begin{array}{c}42 \\
{[33 ; 45]}\end{array}$ & $\begin{array}{c}46 \\
{[37 ; 56]}\end{array}$ & $\begin{array}{c}49.5 \\
{[40 ; 54]}\end{array}$ \\
\hline $\begin{array}{l}\text { The sagittal sizes of } \\
\text { pituitary tumor }(\mathrm{mm}) \text { : }\end{array}$ & $\begin{array}{c}35 \\
{[31 ; 43]}\end{array}$ & $\begin{array}{c}43.5 \\
{[41.5 ; 59]}\end{array}$ & $\begin{array}{c}53 \\
{[39.5 ; 65.5]}\end{array}$ \\
\hline $\begin{array}{l}\text { The frontal sizes of } \\
\text { pituitary tumor }(\mathrm{mm}) \text { : }\end{array}$ & $\begin{array}{c}42 \\
{[36 ; 46]}\end{array}$ & $\begin{array}{c}50 \\
{[32 ; 58]}\end{array}$ & $\begin{array}{c}47 \\
{[37 ; 60]}\end{array}$ \\
\hline
\end{tabular}

\section{RESULTS}

In our cohort of patients with pituitary macroadenomas we found $30(8.6 \%)$ giant pituitary tumors: $18 / 142$ non-functional adenomas (12.7\%); 6/62 macroprolactinomas $(9.7 \%)$; $6 / 141$ somatotropinomas $(4.3 \%)$.

Patients' characteristics and pituitary macroadenoma sizes are summarized in the Tab. 1. Patients with giant prolactinomas and somatotropinomas were under 50 years old and 2025 years younger compared with NFA group.

Giant NFA were met more often than prolactinomas and somatotropinomas, however the median tumor volume was lower the in hormonally active pituitary tumors: NFA 28,190 $[21,143 ; 44,896] \mathrm{mm} 3$, prolactinomas 48,091 [30,331; 97,843] $\mathrm{mm} 3$ and somatotropinomas 51,209 [36,703; 102,207] mm3 (Fig.1).

The most often observed tumour growth directions were supra-latero-infrasellar $(n=19$, $63.3 \%)$, and supra-latero-sellar ( $n=6,20 \%)$ (Fig.2).

Chiasm compression visualized on MR-images in $24(80 \%)$ patients (18 NFA, 3 prolactinomas and 3 somatotropinomas).

Main complains were visual impairment (18 patients, 60\%) and headache (12 patients, $40 \%$ ) (Fig.3) and most often "first referred" specialists were ophthalmologist and neurologist in $15(50 \%)$ and $11(36.7 \%)$ cases, accordingly (Fig.4).

Hypopituitarism before any treatment was found in $10(33.3 \%)$ cases $(7$ NFA, 1 prolactinoma, 2 somatotropinomas), all tumors had vertical size $>40 \mathrm{~mm}$ and significant suprasellar extension.

\section{Gonclusion}

We found the higher prevalence of the giant NFA compared with the hormonally active pituitary adenomas ( $60 \%$ vs $40 \%$ correspondently).

Patient's age $<50$ y.o. and tumor volume $>70,000 \mathrm{~mm}^{3}$ were predictors of hormonal activity of giant adenoma.

The vertical size $>40 \mathrm{~mm}$ and suprasellar extension were predictors of hypopituitarism. The ophthalmologist and neurologist should be aware of giant adenomas.
Fig.1.Pituitary tumour volumes

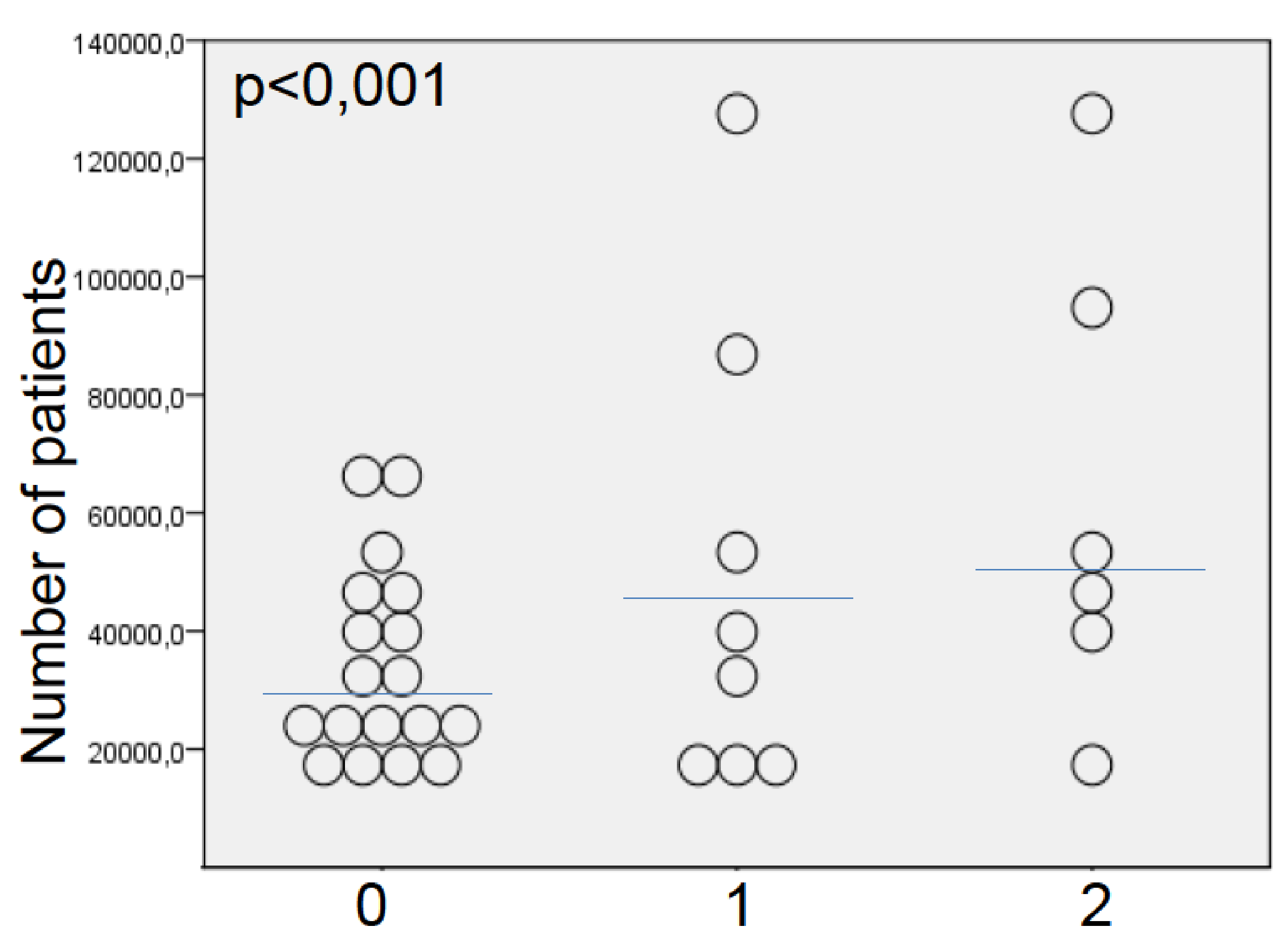

Fig. 2. Directions growth in pituitary macroadenomas (\%)

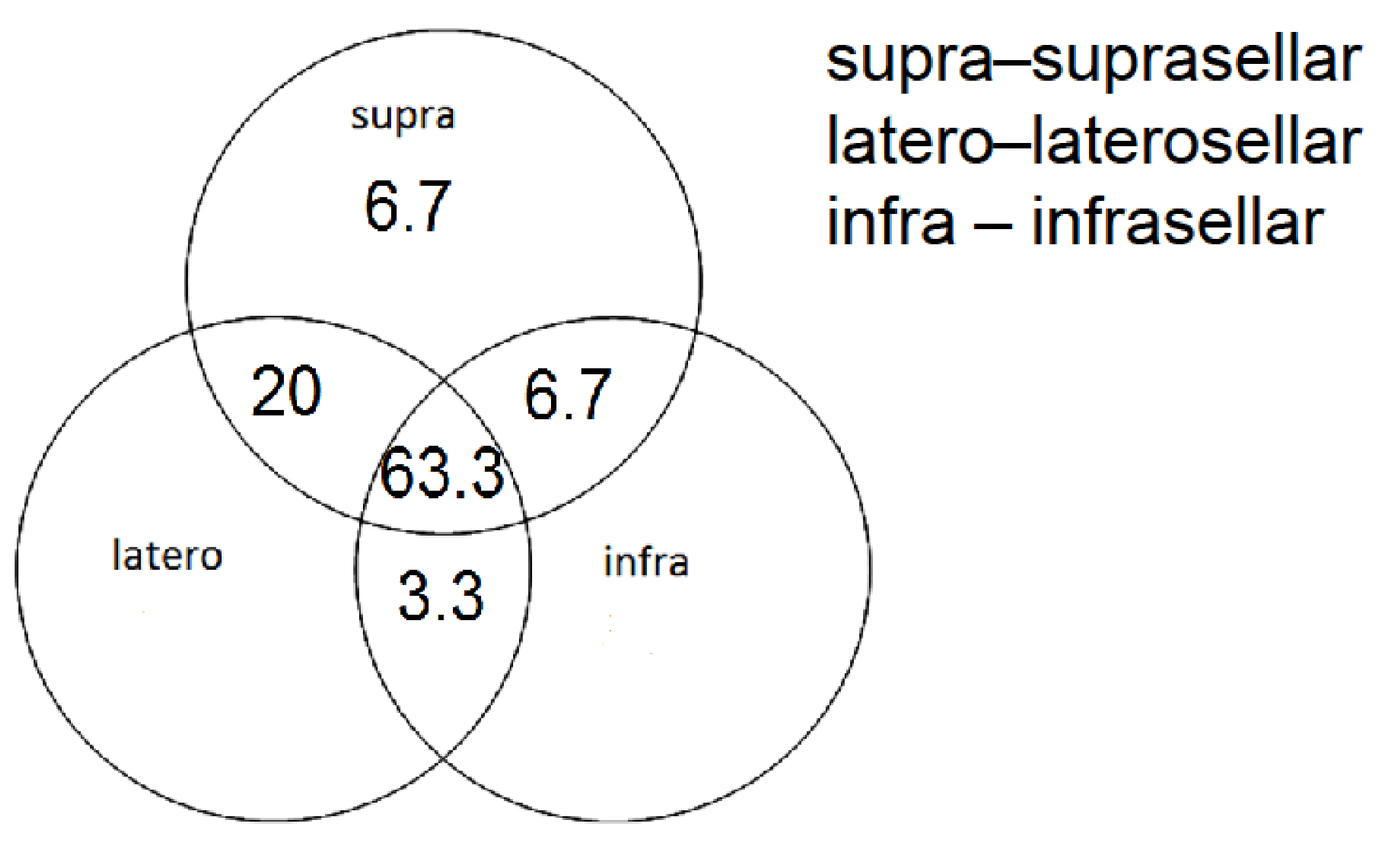

Fig. 3 Main complains the patients

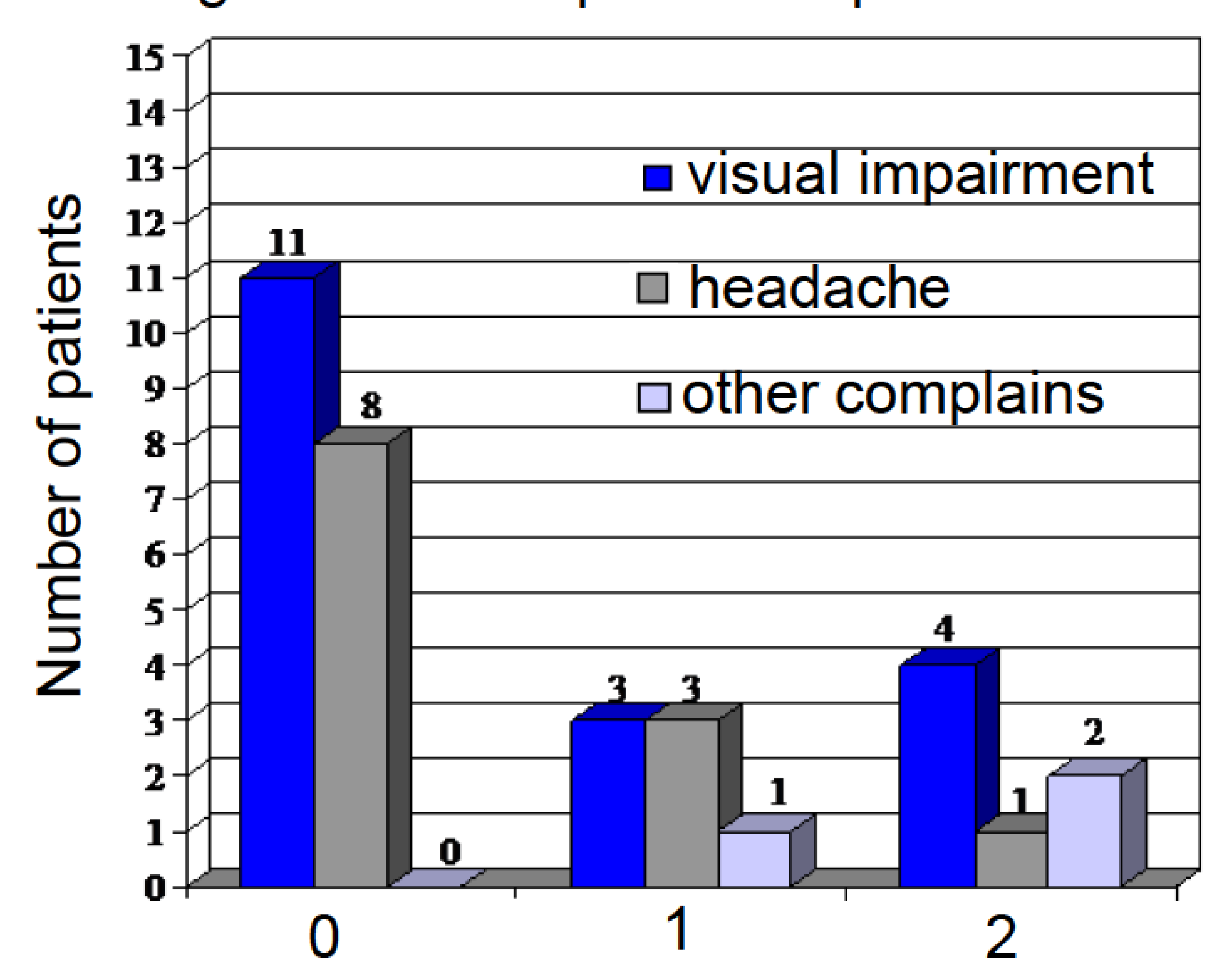

Fig. 4 "First referred" specialists

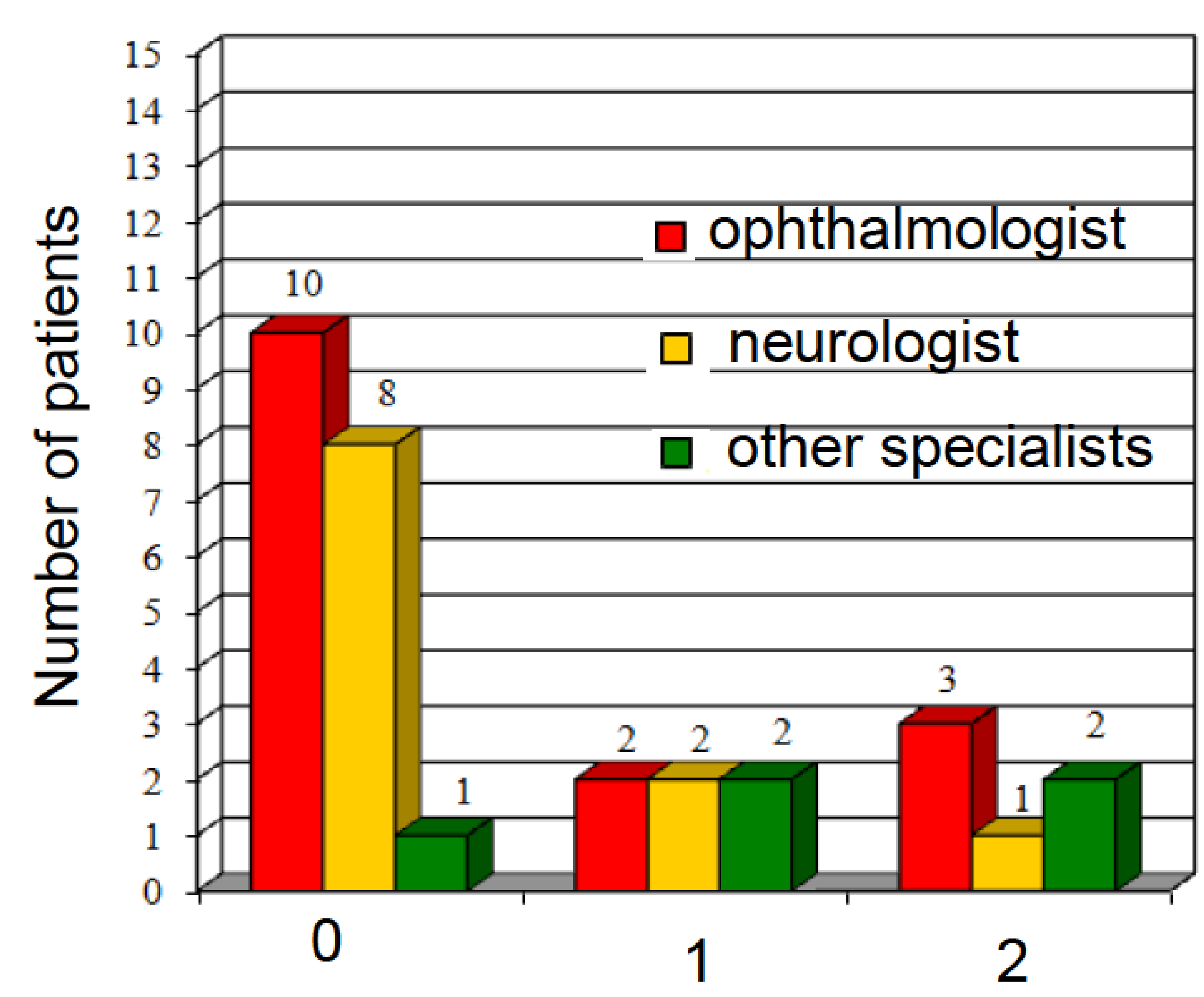

GONTAGT INFORMATION

Irena llovayskaya irena.ilov@yandex.ru Yulya Krivosheeva yulya.k.89@inbox.ru Alexander Dreval dreval@diabet.ru 